Marine and Freshwater Behaviour and Physiology

June 2003; 36(2) : 77 - 86

http://dx.doi.org/ 10.1080/1023624031000109864

(c) 2003 Taylor \& Francis
Archimer http://www.ifremer.fr/docelec/ Archive Institutionnelle de l'Ifremer

The original publication is available at http://www.tandf.co.uk/journals/

\title{
Feeding Responses of Hatchery-Reared Gilthead Sea Bream (Sparus aurata L.) to a Commercial Diet and Natural Prey Items
}

\author{
J.E. Andrew ${ }^{1}$, M.L. Bégout Anras ${ }^{2 \star}$, S. Kadri ${ }^{1}$, J. Holm ${ }^{3}$, F.A. Huntingford ${ }^{1}$ \\ ${ }^{1}$ Division of Environmental and Evolutionary Biology Institute of Biomedical and Life Sciences Graham Kerr \\ Building, University of Glasgow Glasgow UK G12 8QQ \\ ${ }^{2}$ Centre de recherche sur les Ecosystèmes Marins et Aquacoles (CNRS/IFREMER) B.P.5 17137 L'Houmeau \\ France \\ ${ }^{3}$ Biomar A/S Mylius Erichsensvej 35 DK-7330 Brande Denmark \\ *: Corresponding author : Marie.Laure.Begout@ifremer.fr
}

\begin{abstract}
Many fish species have evolved feeding mechanisms and behaviours enabling them to feed on specific prey. However, such mechanisms may not be optimal for feeding on commercial-pelleted diets in aquaculture. Gilthead sea bream chew and occasionally eject pellets or parts of pellets from the mouth when feeding on commercial diets. This may result in an increase in nutritional waste from the intensive culture of this species. In this study we examined the prevalence of this food processing behaviour in two sizes of sea bream, feeding on three types of natural prey items in comparison to a commercial pellet, to give an insight into the circumstances in which excess chewing and ejection of food items from the mouth occurred. These included two hard-textured food items (commercial pellet and hard-shelled prey) and two soft-textured food items (larvae and small crustacean). Both sizes of sea bream frequently consumed the soft-textured food types, however large sea bream also frequently consumed hard-textured pellets. Hard-textured food required longer handling times and elicited more chewing and the ejection of food items from the mouth. These results suggest that future investigations on the food processing behaviour and consequent waste when fed commercial diets differing in texture could give an insight into improving diets and feeding efficiency for intensively cultivated gilthead sea bream.
\end{abstract}

Keywords: Aquaculture, Chewing, Food Choice, Food Handling, Gilthead Sea Bream 


\section{INTRODUCTION}

Recent and continuing expansion of gilthead sea bream (Sparus aurata L.) cage farming has led to concerns over the ecological impact it has on the environment and to a sharp decline in price due to the volume of fish being produced outstripping demand (Barnabé, 1989). To combat this downward pressure on prices, farms have to seek ways to reduce the cost of producing fish. One option is to minimise food wastage and improve feeding efficiencies. Considerable research has been geared towards determining quantitative and qualitative biochemical constituents of artificial diets to improve feeding efficiency (Thorpe and Cho, 1995). Yet limited information is available with respect to palatability.

Various feeding mechanisms and behaviours have evolved in many teleostean fishes, allowing them to either increase the variety of prey they successfully consume or specialise in feeding on certain prey types (Sanford, 2001; Grubich, 2000; Wainwright and Friel, 2000; Frost and Sanford, 1999; Nemeth, 1997; Vandewalle et al., 1995). However, such mechanisms may affect feeding efficiency when fish are fed on commercial diets in aquaculture. It has been observed that gilthead sea bream masticate and occasionally eject pellets or parts of pellets from the mouth during feeding. This food processing behaviour has been described for another sparid species, Diplodus sargus L. by Vanderwalle et al., (1995) when feeding on natural prey items, but has only been referred to in gilthead sea bream as 'playing with' or 'tasting' with regard to pellets in commercial feeding manuals (Artigas, 1999). This food processing comprises of the mouth opening and seizing the food item, which is then subjected to 'chewing' movements. The word 'chewing' refers to movements involving mouth opening and closing or a series of such movements. When the mouth opens, protrusion may occur to a variable degree that may result in food items being ejected from the mouth and on some occasions re-ingested. This complicated oral mastication of prey differs from that observed by other animal species. However, for ease of communication, this will henceforth be referred to as 'chewing'. The food processing behaviour in sea bream may be a consequence of the mouth morphology being suited for browsing. Wild sea bream have been observed to feed by grazing for prey on rocky surfaces (Andrade et al., 1996) consuming a variety of prey with crustaceans, molluscs, polychaetes, teleosts and echinoderms as the major dietary groups (Wassef and Eisawy, 1985). However, the prey consumed varies with fish size. Wassef and Eisawy (1985) found that soft-bodied animals such as polychaetes and small crustaceans dominated the stomach contents of small sea bream (5-9cm in length). The stomach contents of larger sea bream (10$>25 \mathrm{~cm}$ in length) consisted of larger, hard-shelled prey such as barnacles, bivalves and other teleosts. In aquaculture conditions, ejecting pellets from the mouth may result in an increase in waste pellets if not consumed by other fish in the cage. Excessive chewing however may also increase waste if pellets are broken up and particles released from the mouth and gill slits. This is an important consideration, not only when feeding sea bream on a commercial scale but also in feeding trials. If pellets or parts of pellets are being lost during feeding then this may not only increase the quantity of waste passing into the surrounding environment but may also have a significant impact on food conversion ratios. 
The aim of this study was to examine this food processing behaviour when feeding on commercial pellets in comparison to prey items similar to that found in the stomach contents of wild sea bream in order to give an insight into the circumstances in which excess chewing and ejection of food items from the mouth occurs. Pellets differ in many respects from the natural prey of wild fish and it has been proposed that natural prey could possess attractive and palatable qualities lacking in commercial diets. These could be used in the development of diets to suit particular species of farmed animals (Stradmeyer and Thorpe, 1987). Based on this proposal, some studies have examined the feeding behaviour of fish and other animal species when fed natural prey in comparison to commercial feed. Stradmeyer and Thorpe (1987) presented both dry pellets and a range of wild prey organisms to hatchery reared Atlantic salmon (Salmo salar L.) parr. They stated that 'naive hatchery reared salmon readily consumed unfamiliar wild prey, quickly developing a preference for it over pelleted food, responding much more rapidly to wild prey than to a pelleted diet'. A similar study was conducted by Morpurgo et al. (1991) on commercially raised Nile crocodiles, Crocodylus niloticus (Laurenti) where live fish were found to be preferred over commercial feed. If chewing and ejection of food from the mouth by sea bream is required in order for successful consumption of certain types of food items, then by using data gained from this study a pellet may be designed in order to reduce this food processing behaviour and possible consequential waste. Since sea bream of different sizes appear to feed on different prey items in the wild this behaviour may vary with fish size, so the feeding behaviour of two sizes classes of sea bream were examined in this study.

\section{METHODS}

Two hundred hatchery reared gilthead sea bream of mean weight $12 \mathrm{~g}$ (small), and 30 of mean weight $215 \mathrm{~g}$ (large) were held in tanks (1 $\mathrm{m} \times 1 \mathrm{~m} \times 0.5 \mathrm{~m})$ at the CREMA laboratories in L'Houmeau, France $\left(1.10^{\circ} \mathrm{W}: 46.10^{\circ} \mathrm{N}\right)$ over the experimental period from mid May until mid June 2001. For 10 days prior to and throughout the trial period they were fed a mixture of pellets and natural prey (killed just prior to feeding) at a ration of $2 \% \mathrm{BWd}^{-1}$ by hand, to below satiation. Water temperature was ambient and varied from $13.4-23.5^{\circ} \mathrm{C}$, salinity remained constant at $25 \%$ and the fish were exposed to natural photoperiod. Glass tanks $(0.6 \mathrm{~m} \times 0.3 \mathrm{~m} \times 0.35 \mathrm{~m})$ were used as observation chambers. For the small sea bream the tanks were split into two chambers using a glass divider $(0.6 \mathrm{~m} \times 0.15 \mathrm{~m} \times 0.35 \mathrm{~m})$. A plastic tube $(3 \mathrm{~cm}$ diameter) protruding $10 \mathrm{~cm}$ below the surface served as a feeding tube, through which the food items were dropped by hand. This ensured that all food items were presented in the same area. An air stone was placed in one corner of every observation chamber but the air supply was switched off before each trial to prevent water circulation having an influence on the movement of food items in the water column. Sea bream held in isolation were not found to feed, possibly due to stress, therefore 48 hours before each trial, pairs of sea bream were weighed and measured, then moved to an observation chamber. Each pair was in view of another pair at all times either through the glass dividers or from another observation tank. No feed was administered during this acclimation period. A black plastic sheet surrounded the observation chambers to conceal the observer. Pairs of small sea bream were observed for one trial and then returned to a holding tank, whereas the large sea 
bream were observed for two trials in succession due to a smaller number of fish to increase sample size.

The small sea bream were fed prey items similar in size to $2 \mathrm{~mm}$ pellets and the large sea bream were fed prey items similar in size to $4 \mathrm{~mm}$ pellets. The food items differed in several characteristics but were chosen so as to present both group sizes with softbodied and hard-textured food types (for details of food items see Table 1). All live prey items were killed just prior to presentation. In each trial each pair of sea bream were presented with the 4 different food items allocated to their group one at a time. Each trial differed in the order these were presented. Forty-eight trials were run in total for the small sea bream and 30 trials for the large sea bream. Each food item was presented either immediately after the previous had been consumed or if not consumed, 5 minutes after the previous food item had been presented. Only one fish in each pair fed during each trial and this fish was identified and any interactions during the trials between the pair noted. There were no observed incidences of aggressive or competitive interactions in any of the trials. This may have been due to dominance interactions occurring and being settled in the 48 hours of acclimation prior to the trials, resulting in only the dominant fish feeding.

Table 1. Descriptions for food items fed to small and large sea bream with mean dimensions $(\mathrm{mm}) \pm \mathrm{SE}(\mathrm{N}=48$ for small sea bream food items and $\mathrm{N}=30$ for large sea bream food items). $\mathrm{L}=$ length, $\mathrm{D}=$ diameter, $\mathrm{W}=$ width, $\mathrm{H}=$ height.

\begin{tabular}{ccccc}
\hline Fish Size & \multicolumn{2}{c}{ Small } & \multicolumn{2}{c}{ Large } \\
\hline Food type & Food item & Mean dimensions & Food item & Mean dimensions \\
\hline Pellet & Biomar & D: $1.9 \pm 0.04$ & Biomar & D: $4.0 \pm 0.04$ \\
& Ecostart & L: $2.3 \pm 0.05$ & Ecolife & L: $4.2 \pm 0.09$ \\
\hline Hard-shell & Laver spire snail & H: $2.7 \pm 0.14$ & Mussel & H: $14.5 \pm 0.36$ \\
& (Hydrobia ulvae) & D: $1.5 \pm 0.04$ & (Mytilus edulis) & D: $7.6 \pm 0.25$ \\
\hline Crustacean & Gammarid & L: $8.1 \pm 0.23$ & Crustacean & L: $13.1 \pm 0.25$ \\
& (Gammarus locusta) & H: $2.2 \pm 0.07$ & (Idotea graviculosa) & H: $1.6 \pm 0.12$ \\
& & W: $1.2 \pm 0.06$ & & W: $2.6 \pm 0.25$ \\
\hline Larvae & Chironomid larva & D: $0.8 \pm 0.03$ & Beetle Larva & D: $2.7 \pm 0.07$ \\
& & L: $12.1 \pm 0.28$ & & L: $10.9 \pm 0.14$ \\
\hline
\end{tabular}

The behaviours recorded were whether the food item was approached and the time taken to reach it. It was then noted whether the food item was ingested, rejected or disregarded. Rejection was defined as a food item being taken into the mouth and being ejected a single time. The food item was noted as disregarded if it was not approached or if it was approached, not taken into the mouth. If ingested, the number of chews and the number of times the food item was ejected and then re-ingested in order to consume the food items were recorded. 'Chewing' was defined as a jaw movement once the food item was seized and 'ejection' as a protrusion of the food item from the mouth and then re-ingestion. Total handling time was calculated as the time from ingestion until no mouth movements were observed with successfully consumed food items. 
$\mathrm{Chi}^{2}$ and Kruskal-Wallis tests were used to examine whether there were any differences found between tanks for any of the behaviours studied or between the order in which food items were presented to the sea bream. No significant differences were found therefore order of presentation was disregarded and data from different tanks combined.

$\mathrm{Chi}^{2}$ tests were used to analyse for differences between the proportion of food items ingested, rejected or disregarded within each size group. When comparing the time to reach the food items and total handling times, one-way ANOVA's were used for small sea bream and Kruskal-Wallis tests for large sea bream as these data were not normally distributed. To compare the number of chews and ejection's elicited in order to consume the different food items Kruskal-Wallis tests were used for both size groups. Significance in all tests was accepted at $\mathrm{P}<0.05$.

When looking for correlations between temperature, fish size, handling times, and food manipulation, a Pearson's product-moment correlation was applied. Significance was accepted using the sequential Bonferroni technique (Rice, 1989) at the 'table-wide' 0.05 level. All calculations were carried out using the Minitab 11.0 statistical package (Minitab Inc, PA).

\section{RESULTS}

Frequency of Ingestion and Rejection

Differences in the probability of ingestion and rejection were found between food types. For the small sea bream a significantly greater proportion of chironomid larvae and crustaceans were successfully ingested and a significantly lower proportion rejected in comparison to pellets and sea snails $(\mathrm{P}<0.001$, Figure $1 \mathrm{a})$. For the large sea bream the soft-bodied beetle larvae and crustaceans were frequently consumed, but pellets were also consumed frequently. Only mussels were regularly rejected with only c. $50 \%$ being successfully consumed $(\mathrm{P}<0.001$, Figure $1 \mathrm{~b})$. 
Figure 1 Frequency of food items ingested, rejected and disregarded for a) small and b) large gilthead sea bream.

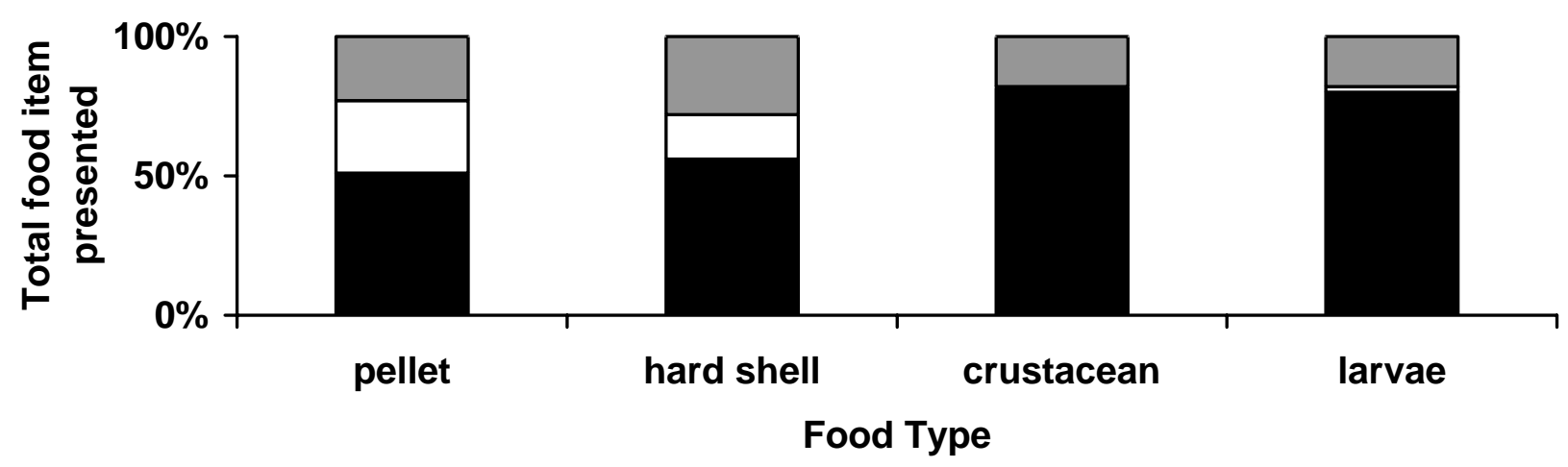

b ingested $\square$ rejected $\square$ disregarded

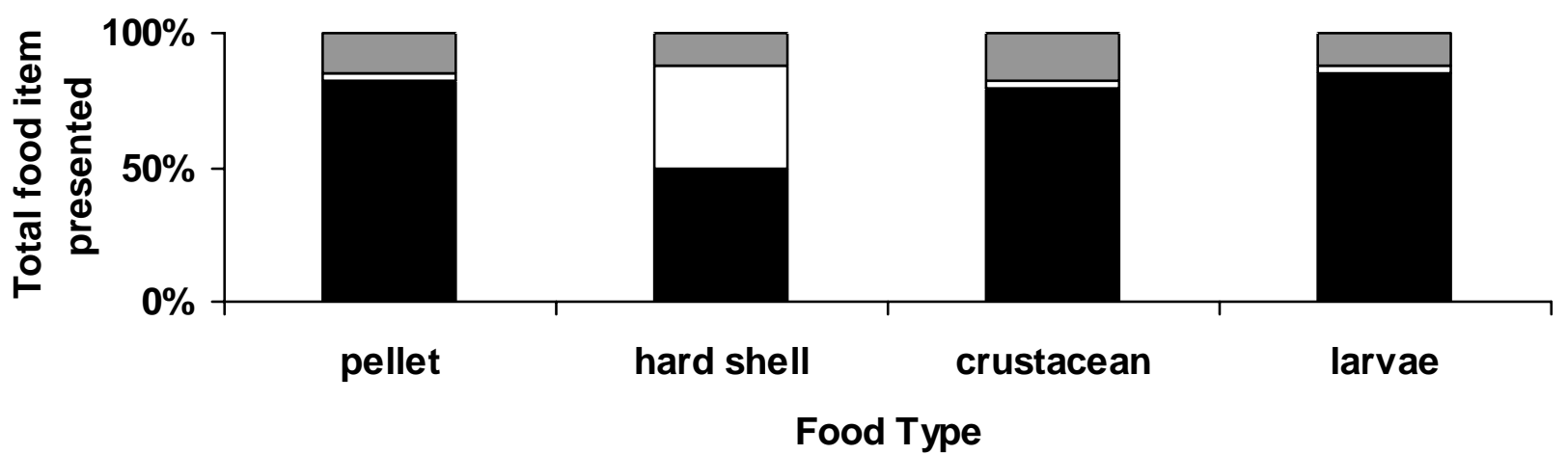

Time to Reach Prey

In no group was there a significant difference in the time taken to reach the different types of food items (small sea bream: $\mathrm{P}=0.215$; large sea bream: $\mathrm{P}=0.312$ ).

Total Handling Times

Overall handling times varied significantly between food types (Figure 2). The small sea bream took significantly longer to consume pellets and sea snails than the larvae or crustaceans $(\mathrm{P}<0.001)$. Overall handling times also varied with prey type for the large sea bream, with hard-textured mussels and pellets taking longer to consume than the larvae and crustaceans $(\mathrm{P}<0.001)$. 
Figure 2 The mean total handling time (seconds) \pm SE taken to consume the food items for large and small gilthead sea bream.

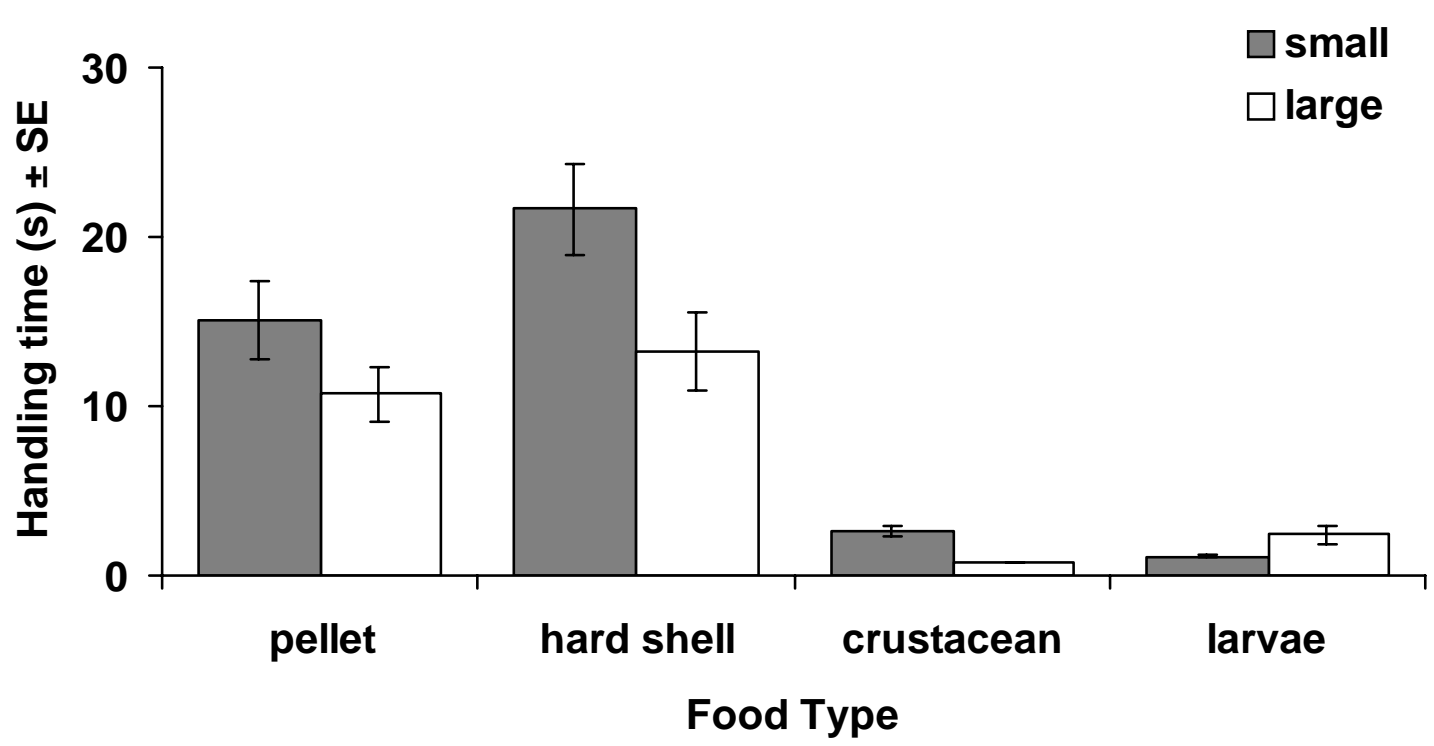

Prey Manipulation

Manipulation of ingested food items also varied between food types. The number of chews observed was higher when the small bream ingested sea snails in comparison to that observed for pellets, and both were chewed significantly more than the larvae and crustaceans $(\mathrm{P}<0.001$, Figure 3a). There were no differences between the number of chews needed to consume a larvae or crustacean. The large bream followed a similar pattern. The hard-textured pellets and mussels required more chewing for successful ingestion than did the crustaceans or larvae $(\mathrm{P}<0.001)$. In both size groups the number of observed food ejection's followed a similar pattern to chewing (small sea bream: $\mathrm{P}<0.001$; large sea bream: $\mathrm{P}<0.001$ ) with hard-textured prey items eliciting more ejection's from the mouth (Figure $3 b$ ). 
Figure 3 The mean number of a) chews during mastication and b) ejection of food items from the mouth \pm SE elicited to consume the food items for large and small gilthead sea bream.

a

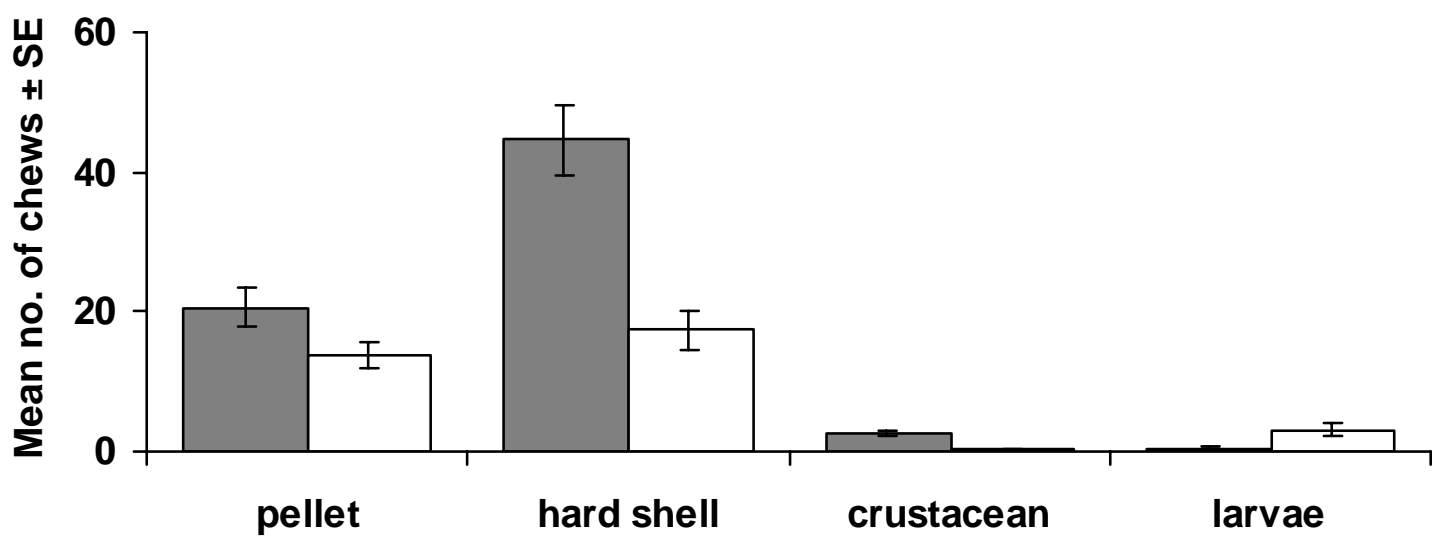

Food Type

b

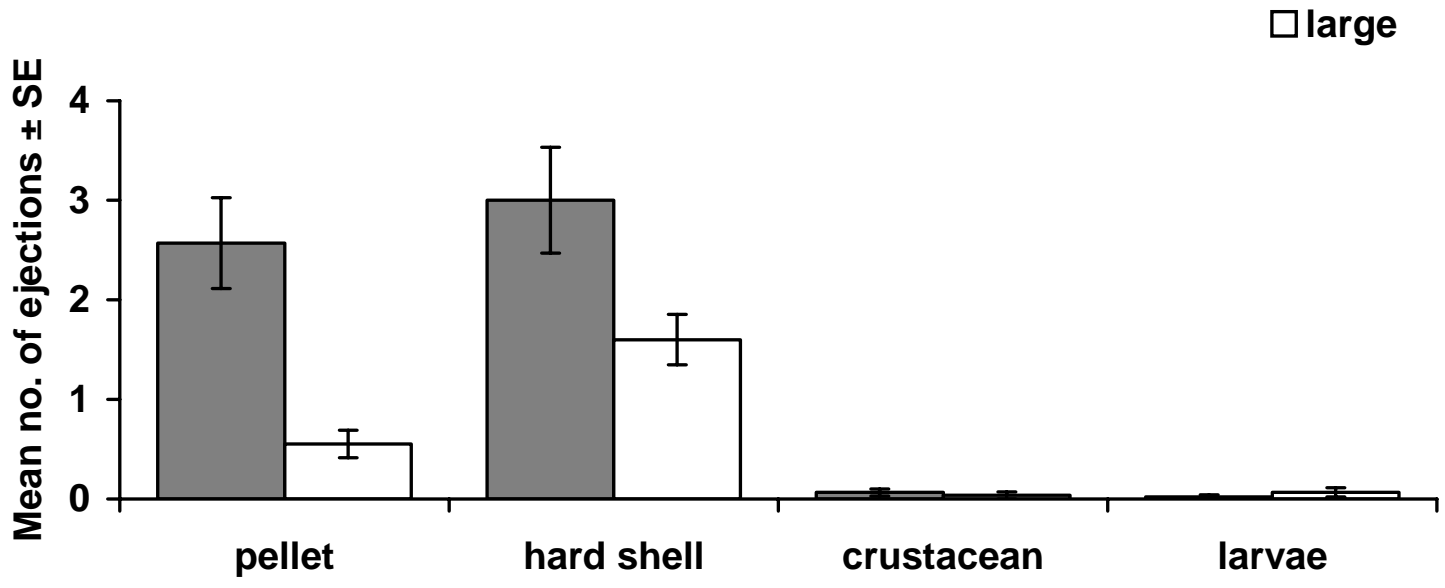

Food Type

Relationship Between Handling Times and Manipulation

For all food types in both size groups there was a positive correlation between chewing and handling time (Table 2). It was also observed that handling time $(r=0.779, \mathrm{~N}=32$, $\mathrm{P}<0.001)$ and chewing $(r=0.732, \mathrm{~N}=41, \mathrm{P}<0.001)$ positively correlated with the number of ejection's of hard-shelled sea snails from the mouths of the small sea bream. 


\section{Temperature Effects}

Since the water temperature could not be controlled and fluctuated naturally, it was measured before each trial but did not appear to have an effect on the feeding behaviours recorded. Correlations between temperature and the total handling time, chewing and ejection of food items for both sizes of sea bream all lacked significance.

Table 2. Pearson's Product moment correlation's for handling time vs. chewing for all food items in both size groups. Statistical significance was accepted 'table-wide' at the 0.05 level using the Sequential Bonferroni technique.

\begin{tabular}{ccccccc}
\hline Fish size & \multicolumn{2}{c}{ Small } & \multicolumn{3}{c}{ Large } \\
Food type & $r$ & $\mathrm{~N}$ & $\mathrm{P}$ & $r$ & $\mathrm{~N}$ & $\mathrm{P}$ \\
\hline Pellet & 0.681 & 29 & $<0.001$ & 0.772 & 28 & $<0.001$ \\
Hard shell & 0.823 & 32 & $<0.001$ & 0.756 & 25 & $<0.001$ \\
Crustacean & 0.825 & 46 & $<0.001$ & 0.622 & 27 & 0.001 \\
Larvae & 0.546 & 46 & $<0.001$ & 0.848 & 29 & $<0.001$ \\
\hline
\end{tabular}

\section{DISCUSSION}

Small sea bream consumed soft-textured food items such as larvae and small crustaceans more frequently than hard-textured sea snails and pellets. Although large sea bream ate the soft-textured food items frequently, hard-textured pellets were also frequently consumed. Therefore, food acceptance appears to be more flexible for the large sea bream. This supports the data found from the stomach contents of wild caught sea bream by Wassef and Eisawy (1985), where soft-bodied animals dominated the stomach contents of the small sea bream compared to the variety of both hard-shelled and soft-bodied prey found in the stomachs of larger sea bream. Nutritional content of the food items can also influence food consumption, which was not measured in this study. However, commercial pellets are designed to have a higher nutritional content than natural prey items and pellets were not frequently consumed by the small sea bream in this study. Therefore, nutritional content of the food is not the only factor involved in food selection and acceptance.

Much feeding behaviour appears to be developmentally fixed in a number of species such as the technique used to feed on live mussels by juvenile rock lobsters, Jasus edwardsii (James and Tong, 1998) and the aquatic strike feeding behaviour of the Salamander, Salamandra salamandra (Reilly, 1995). Some species however have the ability to modulate feeding mechanisms and behaviour but this varies greatly among taxa (Herrel et al., 2001; Marshall et al., 2000; Lentle et al., 1999; Pérez-Barbería and Gordon, 1998; Ginnet and Demment, 1997; Howse et al., 1995). Muscle activation patterns underlying feeding in teleost fishes appear to be highly variable and can be altered in response to prey type by individual fish (Wainwright and Friel, 2000). For example, the knife fish, Chitala chitala Hamilton (Frost and Sanford, 1999) can modulate open-mouth chewing when feeding on fish and worms as can the Brook trout, Salvelinus fontinalis Mitchill (Sanford, 2001). The white bream, Diplodus sargus, can 
modulate its crushing movements to be either fast, ample or slow and the frequency of ejection of prey from the mouth can vary depending on prey type (Vandewalle et al., 1995). This was also found to be the case for gilthead sea bream. Hard-textured prey required an increase in chewing and ejection from the mouth by both fish sizes in order for successful consumption. Therefore food items that elicit reduced chewing and ejection from the mouth were accepted more readily as food items.

Nagelkerke and Sibbing, (1996) state that the empirical feeding efficiency is largely determined by the time to handle food items rather than by the energy required for specific feeding actions. In this study the time to handle the hard-textured food items was longer than that recorded for the soft-textured food, with handling time being positively correlated to chewing with all food types and also to the ejection frequency of hard-textured sea snails from the mouth of the small sea bream. Therefore the sea bream fed more efficiently on softer textured prey. Chewing was also positively correlated to the ejection frequency of hard-shelled sea snails when fed to the small sea bream. This suggests that for food items that required prolonged chewing, the ejection of food items and subsequent re-ingestion may be used to reposition the food item in the mouth to allow thorough mastication. Large sea bream, although not compared statistically, did appear to manipulate their food items less for successful consumption in comparison to smaller sea bream. They also had shorter handling times, which further supports the hypothesis that large sea bream are more efficient at feeding on hard-textured prey compared to smaller sea bream. This may be due to jaw and mouth development. Sea bream juvenile dentition is composed principally of many small canine-like teeth. As the fish age a more complex heterodont system of canine-like teeth and molar-like plated teeth results (Cataldi et al., 1987). It may only be large sea bream that are able to successfully crush hard-textured prey by using these rows of molar-like teeth. However, shorter handling times in the large sea bream may also have been due to the relation of the pellet size to gape size and oesophagus diameter. If, for example, the $4 \mathrm{~mm}$ pellet fed to the large bream was proportionally smaller than the $2 \mathrm{~mm}$ pellet fed to the small bream, then the large bream would consume the pellet in a shorter space of time. However, both sizes of bream vigorously chewed the pellets during feeding, so were most probably not consuming the pellet whole.

These results give us some insight into the food processing behaviour of the gilthead sea bream and should be taken into consideration when developing commercial diets for this species. Food items, such as small crustaceans and larvae appear to be more readily accepted, as they require low levels of manipulation and reduced handling times. Therefore juvenile sea bream may benefit when fed diets of a softer texture. These diets may elicit less handling and therefore may increase feeding efficiency. However, if juvenile sea bream are more efficient at chewing softer pellets, more particles may be released from the mouth and gill slits leading to an increase in the waste production and food conversion ratio. More detailed studies therefore have to be conducted with gilthead sea bream on the effect of varying pellet texture on the feeding efficiency and subsequent waste production from this food processing behaviour. 


\section{ACKNOWLEDGEMENTS}

Thank you to all staff, especially Jean Paul and Françoise Lagardère, at CREMA L'Houmeau for support during this study. Professor Neil Metcalfe and Dr Jon-erik Juell for helpful suggestions on the experimental set-up and statistical methods, Vendee Aquaculture (La Faute Sur Mer, France) and CREAA (Ile d'Oléron, France) for the supply of sea bream. Thank you also to the COST Action 827 program for funding J. Andrew's travel and subsistence and to two anonymous referees for their helpful comments on the manuscript.

\section{REFERENCES}

Andrade, J.P., Erzini, K. and Palma, J. (1996). Gastric evacuation and feeding in the Gilthead sea bream reared under semi-intensive conditions. Aquacult. Int., 4, 129-141. Artigas, E.G. (1999). Feeding policy for marine fish. ProAqua Nutrición S.A., Spain. Barnabé, G. (1989). Rearing bass and Gilthead bream. In: Barnabé, G. (Ed.), Aquaculture Vol. 2., Ellis Horwood Limited, Chichester.

Cataldi, E., Cataudella, S., Monaco, G., Rossi, A. and Tancioni, L. (1987). A study of the histology and morphology of the digestive tract of the sea-bream, Sparus aurata. J. Fish Biol., 30, 135-145.

Frost, B.J. and Sanford, C.P.J. (1999). Kinematics of a novel feeding mechanism in the osteoglossomorph fish Chitala chitala: is there a prey-type effect? Zool-Anal. Complex Syst., 102, 18-30.

Ginnett, T.F., Demment, M.W. (1997). Sex differences in giraffe foraging behaviour at two spatial scales. Oecologia, 110, 291-300.

Grubich, J.R. (2000). Crushing motor patterns in drum (Teleostei: Sciaenidae): Functional novelties associated with molluscivory. J. Exp. Biol., 203, 3161-3176.

Herrel, A., Meyers, J.J., Nishikawa, K.C. and De Vree, F. (2001). The evolution of feeding motor patterns in lizards: modulatory complexity and possible constraints. Amer. Zool., 41, 1311-1320.

Howse, A.J., Semiadi, G., Stafford, K.J., Barry, T.N. and Muir, P.D. (1995). Digestion and chewing behaviour of young sambar and red deer consuming a low quality roughage. J. Agric. Sci., 125, 399-405.

Lentle, R.G., Stafford, K.J., Potter, M.A., Springett, B.P. and Haslett, S. (1999). Ingesta particle size, food handling and ingestion in the tammar wallaby (Macropus eugenii Desmarest). Aust. J. Zoo., 47, 75-85.

Marshall, C.D., Kubilis, P.S., Huth, G.D., Edmonds, V.M., Halin, D.L. and Reep, R.L. (2000). Food-handling ability and feeding-cycle length of manatees feeding on several species of aquatic plants. J. Mammal., 81, 649-658.

Morpurgo, B., Gvaryahu, G. and Robinzon, B. (1991). Food preference, fish attractability and behaviour manifested toward new feed in young Nile crocodiles, Crocodylus niloticus. Physiol. Behav., 50, 1-4.

Nagelkerke, L.A.J. and Sibbing, F.A. (1996). Efficiency of feeding on zebra mussel (Dreissena polymorpha) by common bream (Abramis brama), white bream (Blicca bjoerkna), and roach (Rutilus rutilus): the effects of morphology and behavior. Can. J. Fish. Aquat. Sci., 53, 2847-2861. 
Nemeth, D.H. (1997). Modulation of attack behaviour and its effect on feeding performance in a trophic generalist fish, Hexagrammos decagrammus. J. Exp. Biol., 200, 2155-2164.

Pérez-Barbería, F.J. and Gordon, I.J. (1998). Factors affecting food comminution during chewing in ruminants: a review. Biol. J. Linn. Soc., 63, 233-256.

Rice, W.R. (1989). Analyzing tables of statistical tests. Evolution, 43, 223-225.

Sanford, C.P.J. (2001). Kinematic analysis of a novel feeding mechanism in the brook trout Salvelinus fontinalis (Teleostei: Salmonidae): behavioural modulation of a functional novelty. J. Exp. Biol., 204, 3905-3916.

Stradmeyer, L. and Thorpe, J.E. (1987). The responses of hatchery-reared Atlantic salmon Salmo salar L., parr to pelleted and wild prey. Aquacult. Fish. Manage., 18, 5161.

Thorpe, J.E. and Cho, C.Y. (1995). Minimising waste through bioenergetically and behaviourally based feeding strategies. Water Sci. Technol., 31, 29-40.

Vandewalle, P., Saintin, P. and Chardon, M. (1995). Structures and movements of the buccal and pharyngeal jaws in relation to feeding in Diplodus sargus. J. Fish Biol., 46, 623-656.

Wainwright, P.C. and Friel, J.P. (2000). Effects of prey type on motor pattern variance in Tetraodontiform fishes. J. Exp. Zool., 286, 563-571.

Wassef, E. and Eisawy, A. (1985). Food and feeding habits of wild and reared Gilthead bream Sparus aurata L. Cybium, 9, 233-242. 